\title{
GAMBARAN KOMUNIKASI KERJA, KEPUASAN KERJA DAN KINERJA KARYAWAN TOSERBA YOGYA CABANG SUNDA BANDUNG
}

\author{
Marisa Nurfitrianti \\ Universitas Pendidikan Indonesia \\ marisa.nurfitrianti95@student.upi.edu \\ Sumiyati \\ Universitas Pendidikan Indonesia \\ sumiyati@upi.edu \\ Bambang Widjajanta \\ bambangwidjajanta@upi.edu
}

\begin{abstract}
ABSTRAK
Tujuan - Tujuan penelitian ini adalah untuk mengetahui gambaran komunikasi kerja, kepuasan kerja dan kinerja karyawan.

Desain/metodologi/pendekatan - Desain penelitian ini adalah cross sectional. Penelitian ini menggunakan pendekatan deskriptif dengan metode explanatory survei. Unit analisis karyawan sebanyak 57 responden. Sebuah kuesioner digunakan sebagai instrumen penelitian untuk mengumpulkan data dari responden. Teknik analisis yang digunakan adalah teknik deskriptif dengan menggunakan distribusi frekuensi

Temuan - Berdasarkan hasil penelitian menggunakan analisis deskriptif, didapatkan hasil bahwa komunikasi kerja berada dalam kategori efektif sesuai dengan skor 81,3\%, kepuasan kerja berada dalam kategori tinggi sesuai dengan skor 79,3 \% dan kinerja karyawan berada pada kategori tinggi sesuai dengan skor $77,8 \%$.

Orisinalitas/nilai - Penelitian ini memberikan pemahaman mendasar bagi isu-isu dasar untuk komunikasi kerja, kepuasan kerja dan kinerja karyawan. Perbedaan penelitian ini dengan penelitian sebelumnya adalah terletak pada objek yang merupakan perusahaan dalam industri ritel yaitu Toserba Yogya Cabang Sunda Bandung, dengan variabel yang diteliti yaitu komunikasi kerja, kepuasan kerja, dan kinerja karyawan, serta menggunakan teori atau referensi yang berbeda dengan peneliti sebelumnya.
\end{abstract}

Kata Kunci :, Komunikasi Kerja, Kepuasan Kerja, Kinerja Karyawan

Jenis Artikel : Studi Kasus

\begin{abstract}
Purpose - The purpose of this study is to knowing the description of working communiacation, job satisfaction and employee performance.

Design/methodology/approachh - The design of this study was cross sectional. This research uses descriptive approach with explanatory survey method. A total of 57 respondents were selected using probability sampling. A questionnaire was used as a research instrument to collect data from respondents. Analytical technique used is descriptive technique by using frequency distribution.

Findings - Based on the results of the research using descriptive analysis, the results indicate that the description of working communication is in effective category according to score of representative $81,3 \%$, job satisfaction is in high category according to score of representative

$79,3 \%$, and employee performance is in high category according to score of representative 77,8\%.

Originality/value - This study provides a basis for understanding issues of working communication, job satisfaction, and employee performance. The difference of this study with the previous research is located on the object which is the company in the retail industry that is Toserba Yogya Cabang Sunda Bandung, with the variables studied namely working communication, job satisfaction, and employee performances, and using different theory or reference from previous researcher.
\end{abstract}

Keywords: working communication, job satisfaction, employee performance Article Type : Case Study 


\section{PENDAHULUAN}

Organisaisi

merupakan tempat

berkumpulnya dua orang atau lebih yang saling bekerjasama untuk mencapai tujuan organisasi. Perilaku Organisasi merupakan teori mengenai apa yang karyawan lakukan dalam sebuah organisasi dan bagaimana perilaku mereka dapat berpengaruh terhadap kinerja organisasi tersebut , Robbins \& Judge, (2015:6). Salah satu sumber daya yang paling dibutuhkan dan merupakan aset terpenting bagi organisasi adalah sumber daya manusia, karena untuk mencapai efektifitas dan efisiensi perusahaan tidak dapat tercapai jika tidak didukung oleh sumber daya manusia (Sumiyati, Masharyono, \& Toyib, 2016). Efektifitas dan efisiensi tercapainya tujuan perusahaan tidak akan berhasil tanpa dukungan sumber daya manusia yang berkualitas (Senen, 2008). Kegagalan mengelola sumber daya manusia dapat berdampak pada pencapaian tujuan perusahaan sehingga upaya yang harus dilakukan oleh perusahaan untuk mempertahankan SDM nya yaitu dengan cara meningkatkan kinerja karyawan, karena kinerja karyawan dapat menjaga kelangsungan dan pencapaian tujuan oganisasi (Burma, 2014).

Keberhasilan suatu organisasi dalam pencapaian tujuan tidak dapat dilepaskan dari peran karyawan. Karyawan dalam organisasi bukan semata-mata objek dalam pencapaian tujuan saja tetapi juga sebagai objek pelaku. Tanpa karyawan suatu tujuan tidak dapat mewujudkan rencana yang telah dibuatnya. (Masharyono, Sumiyati, 2016). Hal serupa juga diungkapkan oleh (Zameer, Alireza, Nisar, \& Amir, 2014) bahwa sumber daya manusia mempunyai peran penting dalam mencapai tujuan organisasi, dan tanpa adanya unsur manusia di dalam organisasi, maka tidak mungkin organisasi tersebut dapat mencapai tujuan yang diinginkan (Masharyono, 2015).

Karyawan akan merasa terlibat ketika mereka menemukan motivasi dan keterlibatan dalam pekerjaan mereka serta mendapatkan dukungan yang positif serta beroperasi dalam lingkungan kerja yang efisien (Pan \& Degre, 2015). Karyawan dengan kinerja yang tinggi cenderung lebih aktif, lebih termotivasi untuk berprestasi dan memiliki keinginan untuk memajukan organisasinya (Manzoor, Ullah, Hussain, \& Ahmad, 2011).

Kinerja karyawan merupakan hal yang sangat penting dalam usaha perusahaan untuk mencapai tujuan bisnisnya serta menjadi salah satu faktor utama keberhasilan suatu perusahaan (Masharyono \& Senen, 2015). Hal serupa juga dikemukakan oleh (Nzuve, 2015) bahwa kinerja karyawan merupakan hal penting bagi perusahaan yang berhubungan dengan hasil serta keberhasilan, sehingga harus diarahkan sesuai dengan tujuan organisasi. Kinerja karyawan merupakan suatu hal yang sangat penting dalam upaya perusahaan untuk mencapai tujuannya serta menjadi salah satu faktor utama keberhasilan suatu perusahaan. Pada dasarnya kinerja seorang karyawan merupakan hal yang bersifat individual karena setiap karyawan mempunyai tingkat kemampuan yang berbeda-beda dalam mengerjakan pekerjaannya (Senen, Sumiyati, \& Juliandiny, 2016)

Kinerja karyawan telah menjadi topik yang diteliti oleh Darker sejak tahun 1911 semenjak ilmu manajemen lahir sebagai ilmu (Wibowo, 2014). Beberapa penelitian menyatakan bahwa kinerja karyawan merupakan masalah penting yang dihadapi oleh organisasi. Hal ini membuat para peneliti untuk meneliti lebih lanjut. (Dizgah, Chegini, \& Bisokhan, 2012). Permasalahan mengenai kinerja karyawan juga menjadi salah satu variabel yang sering dipelajari pada ruang lingkup perilaku organisasi dan sumber daya manusia (Elnaga \& Imran, 2013), sehingga upaya untuk memaksimalkan kinerja karyawan menjadi tantangan bagi suatu perusahaan (Iqbal et.al 2013; Shaheen et al., 2013).

Teori yang digunakan untuk memecahkan masalah kinerja karyawan yang rendah dalam penelitian ini yaitu dengan menggunakan pendekatan perilaku organisasi. Peningkatan kinerja karyawan membantu sebuah perusahaan untuk mencapai tujuan yang akan diraih perusahaan, maka kinerja karyawan yang bernilai positif akan memberikan citra yang positif pula untuk perusahaan (Hassan, 2016)

Kinerja yang meningkat terjadi ketika perusahaan memberikan rasa nyaman dan kondisi situasi pekerjaan baik sosial, fisik, maupun psikologis merasa terpenuhi oleh perusahaan, maka dari itu kepuasan kerja sangatlah penting untuk meningkatkan kinerja karyawan (Awan \& Asghar, 2014). Kepuasan kerja yang tinggi juga akan memotivasi karyawan untuk bekerja lebih baik lagi. Apabila karyawan merasakan pekerjaannya secara positif, maka kinerja karyawan akan lebih baik. Hal ini sesuai dengan pendapat (Noe, 2015) yaitu kepuasan kerja yang tinggi membantu organisasi mencapai kinerja yang optimal dan pencapaian tujuan bisnisnya. Rendahnya kepuasan kerja disinyalir dapat di atasi dengan komunikasi kerja yang baik. Seperti hasil penelitian yang dilakukan oleh (Tourani \& Rast, 2012) menemukan bahwa komunikasi yang efektif merupakan elemen penting dari lingkungan organisasi yang dapat meningkatkan kepuasan kerja karyawan. 
Tujuan dari penelitian ini adalah untuk mengetahui gambaran dari komunikasi kerja, kepuasan kerja, dan komunikasi kerja karyawan.

\section{KAJIAN PUSTAKA}

\begin{abstract}
Manajemen Sumber Daya Manusia (MSDM) merupakan pendekatan yang komprehensif dan koheren, dan juga sumber keunggulan dari strategi organisasi dalam mencapai tujuan organisasi (Chinomona, 2014). Salah satu kajian dalam MSDM yaitu Perilaku Organisasi (PO). Sebagaimana yang telah dijelaskan sebelumnya, bahwa pendekatan yang digunakan dalam memecahkan masalah penelitian ini yaitu konsep perilaku organisasi. (Robbins \& Judge, 2015:5)menyatakan bahwa perilaku organisasi adalah bidang studi yang menyelidiki dampak perorangan, kelompok, dan struktur terhadap perilaku dalam organisasi, dengan tujuan untuk menerapkan pengetahuan tersebut untuk memperbaiki efektivitas organisasi. Perilaku organisasi juga merupakan studi mengenai faktorfaktor yang mempengaruhi bagaimana individu dan kelompok yang bertindak dalam organisasi dan bagaimana organisasi menanggapi lingkungan mereka,(George \& Jones, 2015) Secara umum terdapat tiga bagian yang menjadikan Perilaku Organisai (PO) menjadi efektif yaitu individual level, group level, dan organizational level (Robbins \& Judge, 2015:6).
\end{abstract}

Komunikasi kerja termasuk kedalam level kelompok. Komunikasi merupakan hal yang sangat penting dalam suatu organisasi, dan tidak hanya sekedar proses penyampaian suatu informasi yang simbol-simbolnya dapat dilihat, didengar dan dimengerti, melainkan suatu proses penyampaian informasi secara keseluruhan termasuk di dalamnya terdapat perasaan dan sikap dari orang yang menyampaikan hal tersebut (Robbins \& Judge, 2015:223). Disisi lain, komunikasi yang efektif tidak hanya diperlukan untuk hubungan manusia tetapi untuk kesuksean organisasi dalam mencapai tujuannya (Singh, 2014). Sebab menurut (Husain, 2013), komunikasi sangat penting bagi efektivitas suatu organisasi dan dalam kenyataanya tidak ada organisasi yang dapat berjalan tanpa adanya suatu komunikasi (Spaho, 2011).

Komunikasi merupakan alat utama untuk menyempurnkan hubungan kerja di dalam suatu organisasi. Apabila tidak ada komunikasi, maka akan mengakibatkan kesalahpahaman, dan jika diabaikan dapat mempengaruhi kinerja karyawan (Ismail, Mohamed, \& Rayee, 2016). Menurut Robbins \& Judge (2015) komunikasi merupakan pemindahan dan pemahaman arti dari individu ke individu lain. Komunikasi adalah pertukaran informasi antara pemberi informasi dan penerima, dan menarik kesimpulan sebagai persepsi tentang makna sesuatu antara individual yang terlibat (Kreitner \& Kinicki, 2014)

Jenis komunikasi apabila dilihat dari aspek kehidupan organisasi dalam prosesnya terdiri dari dua dimensi yaitu dimensi komunikasi internal dan dimensi komunikasi eksternal. Komunikasi interndal terjadi dalam suatu organisasi yang terdiri dari seluruh karyawan semua level yang disebut publik internal. Sedangkan komunikasi eksternal adalah komunikasi yang dilakukan organisasi pada publik yang dijadikan sasaran atau target segmentasi (Effendy, 2012:112)Komunikasi dilihat dari aspek polanya terdiri dari downward communication, upward communicatin, dan horizontal communication (Gomez-Mejia \& Balkin, 2012). Menurut Robbins \& Judge (2015) komunikasi dapat mengalir secara vertikal atau lateral. Lebih lanjut lagi dimensi vertikal dapat dibagi menjadi komunikasi ke arah bawah ( Downword Communication) dan ke atas (Upward Communication), serta Lateral Communication.

Fungsi komunikasi dalam suatu organisasi merupakan sarana untuk memadukan tugas-tugas agar dapat terorganisasi. Komunikasi yang efektif sangat penting karena dapat mempengaruhi hamper setiap aspek dalam perilaku organisasi. (George \& Jones, 2015) berpendapat bahwa, komunikasi yang efektif antara manajer dan karyawan memiliki fungsi penting dalam organisasi antara lain menyediakan pengetahuan, memotivasi anggota organisasi, pengendalian dan koordinasi kegiatan kelompok, dan mendorong ekspresi perasaan dan emosi. Robbins \& Judge (2015) menyatakan ada empat fungsi utama komunikasi di dalam kelompok atau organisasi, yaitu: pengendalian, motivasi, pernyataan emosional, dan informasi. (Wilson, 2012:361) mengemukakan bahwa terdapat empat fungsi komunikasi dalam organisasi antara lain sebagai pengawasan, memotivasi, ungkapan emosi dan informasi. (Poppy, 2014) menyatakan ada dua fungsi komunikasi yaitu fungsi komando dan fungsi relasi yang mendukung organisasi dalam pengambilan keputusan, terutama ketika organisasi menghadapi situasi yang kurang menentu. Selanjutnya Robbins dan Judge (2015:241) berpendapat hambatan komunikasi yaitu: 1) filtering (penyaringan), 2) selective perception (selektif persepsi), 3) information overload (informasi yang berlebihan), 4) emotions (emosi), 5) language (bahasa), 6) silence (keheningan), 7) communication apprehension (penangkapan komunikasi) dan 8) lying (bohong).

Proses komunikasi adalah proses yang menggambarkan kegiatan komunikasi antar manusia yang bersifat interaktif, relasional, dan 
transaksional dimana komunikator mengirimkan pesan kepada komunikan melalui media tertentu dengan maksud dan tujuan tertentu (Lubis, 2013). Model komunikasi menggambarkan bagaimana jalannya proses komunikasi, bagaimana komunikasi mengalir melalui saluran komunikasi dari sender, sebagai pengirim kepada receiver, sebagai penerima (Wibowo, 2014)

Menurut (Robbins \& Coulter, 2016:206) sebelum melakukan komunikasi, informasi tersebut harus memiliki tujuan untuk dinyatakan sebagai pesan yang akan disampaikan, antara sumber dan penerima. Pesan tersebut kemudian diubah menjadi bentuk simbolik (encoding) dan disahkan oleh beberapa media (channel) ke penerima, yang menerjemahkan pesan kepada pengirim (decoding). Hasilnya berupa makna dari satu orang ke orang lain. Seluruh proses komunikasi ini sangat rentan terhadap gangguan kebisingan yang dapat menggangu penerimaan, transmisi, atau umpan balik dari pesan.

Kepuasan kerja termasuk ke dalam individual level. Kepuasan kerja pada dasarnya merupakan sesuatu yang bersifat individual. Setiap individu memiliki tingkat kepuasan yang berbeda-beda sesuai dengan sistem nilai yang berlaku pada dirinya. Makin tinggi penilaian terhadap kegiatan dirasakan sesuai dengan keinginan individu, maka makin tinggi kepuasannya terhadap kegiatan tersebut (Alfayad, Suriani, \& Arif, 2017). Kepuasan kerja adalah sebuah perasaan positif terhadap pekerjaan yang dihasilkan dari evaluasi atas karakteristikkarakteristiknya (Robbins dan Judge, 2015). Kepuasan kerja merupakan orientasi emosi yang karyawan memiliki terhadap peran mereka di tempat kerja serta komponen penting untuk motivasi karyawan dan dorongan terhadap kinerja yang lebih baik (Raziq \& Maulabakhsh, 2015). (George \& Jones, 2015)kepuasan kerja adalah kumpulan perasaan dan keyakinan yang dimiliki manusia mengenai pekerjaan yang sedang dijalaninya. Tingkat atau derajat manusia dalam kepuasan kerja dapat berkisar mulai dari kepuasan yang esktrim sampai ketidakpuasan yang ekstrim.

Dimensi kepuasan kerja karyawan menurut ( Schermerhorn, 2010:73), terdiri dari : 1) the work it self (tanggung jawab minat, pertumbuhan kerja), 2) quality of supervision (dukungan sosial dan bantuan teknis), 3) relationship with coworkers (jalinan harmoni dan rasa hormat), 4) promotion (kesempatan untuk kemajuan lebih lanjut, dan 5) pay (kecukupan pembayaran dirasakan). (Alfayad et al., 2017) berpendapat bahwa kepuasan kerja dapat diukur melalui 1) Imbalan, 2) Rekan kerja, 3) Kondisi kerja, dan 4) Faktor lingkungan sekitar.
Robbins dan Judge (2015) mengemukakan bahwa kepuasan kerja dapat diukur dengan 1) sifat pekerjaan, 2) pengawasan, 3) gaji sekarang, 4) peluang promosi, 5) hubungan dengan rekan kerja. Terdapat banyak dimensi yang telah dikaitkan dengan kepuasan kerja, lima dimensi secara khusus yang memiliki karakteristk menurut (Gibson, 2012:102), yaitu 1) Pay (gaji), 2) Job (pekerjaan), 3) Promotion (promosi), 4) Supervisor (supervisi), 5) Coworkers (rekan kerja). Sedangkan menurut (Luthans, 2012) terdapat lima dimensi dalam kepuasan kerja, yaitu 1) The work itself (pekerjaan itu sendiri), 2) Pay (Gaji), 3) Promotion opportunitie (peluang promosi), 4) Supervision (pengawasan), dan 5) Coworkers (rekan kerja). (Kreitner \& Kinicki, 2014) ada lima dimensi dalam kepuasan kerja yaitu sebagai berikut, 1.) Pemenuhan kebutuhan (Need Fulfillment), 2.) Ketidaksesuaian (Discrepancies), 3.) Pencapaian nilai (Value Attainment), 4.) Keadilan (Equity), 5.) Komponen genetic (Genetic components) Penelitian ini menggunakan dimensi kepuasan kerja menurut yaitu 1) Pay (gaji), 2) Job (pekerjaan), 3) Promotion (promosi), 4) Supervisor (supervisi), 5) Coworkers (rekan kerja) karena dimensi yang dikemukakan oleh mereka sudah merangkum aspek-aspek yang ada pada kepuasan kerja karyawan terutama pada objek yang akan diteliti.

Perilaku organisasi merupakan suatu disiplin ilmu yang di dalamnya mengkaji bagaimana tindakan individu dan kelompok dalam suatu organisasi serta dampaknya terhadap kinerja, baik kinerja individual, kelompok maupun kinerja organisasi. Pentingnya mempelajari perilaku karena berkaitan dengan kinerja sumber daya manusia. Kinerja sumber daya manusia akan meningkat apabila perilakunya sesuai dengan tuntutan pekerjaan (Stuart-Kotze ;(Wibowo, 2014).

Kinerja pada dasarnya dapat dilihat dari dua segi, yaitu kinerja karyawan dan kinerja organisasi. Kinerja karyawan dan kinerja organisasi memiliki keterkaitan yang erat. Tercapainya tujuan organisasi tidak dapat lepas dari sumber daya yang dimiliki oleh organisasi yang dijalankan oleh karyawan yang berperan aktif sebagai pelaku dalam upaya mencapai tujuan organisasi tersebut Kinerja yang dihasilkan oleh karyawan sangat berpengaruh bagi kelangsungan suatu organisasi, ini berarti kinerja karyawan merupakan peran penting dalam menentukan keberhasilan organisasi (Irefin \& Mechanic, 2014). Kinerja merupakan hasil pekerjaan yang mempunyai hubungan kuat dengan tujuan strategis organisasi (Wibowo, 2014:7). Kinerja didefinisikan oleh (Armstrong, 2014:247) bahwa Performance is indeed often 
regarded as simply the outcomes archieved : a record of a person's accomplishments yang artinya bahwa, kinerja memang sering dianggap sebagai hasil yang dicapai yaitu catatan prestasi seseorang. Kinerja merupakan prestasi kerja, yaitu perbandingan antara hasil kerja dengan standar yang ditetapkan(Mathis et,al 2010:324) menyatakan bahwa kinerja pada dasarnya adalah apa yang dilakukan atau tidak dilakukan karyawan.

(Gomez-Mejia \& Balkin, 2012:225) mengemukakan bahwa dimensi kinerja terdiri dari: 1) Quality of work (Kualitas pekerjaan), 2) Quantity of work performed (Kuantitas pekerjaan yang dilakukan), 3) Interpersonal effectiveness (Efektivitas interpersonal), 4) Competence (Kompetensi) dan 5. Job Knowledge (Pengetahuan mengenai pekerjaan). Sedangkan menurut Mangkunegara (2013) variabel-variabel yang berhubungan dengan kinerja karyawan diantaranya: 1) Kualitas, 2) Kuantitas, 3) Pelaksanaan Tugas, dan 4) Tanggung Jawab.

Penilaian kinerja adalah evaluasi yang sistematis dari kinerja karyawan dalam tugas nya ditugaskan. Tujuan utama dari penilaian kinerja adalah untuk meningkatkan motivasi dan harga diri karyawan. Penilaian kinerja dapat meningkatkan pertumbuhan profesional dari seorang karyawan (Saira, 2016). (Talasaz, Saadoldin, \& Shakeri, 2014)berpendapat bahwa penilaian kinerja harus secara individual disesuaikan dengan karakteristik karyawannya. Penilaian kinerja juga diartikan sebagai suatu proses manajerial melalaui perilaku karyawan dan prestasi agar dapat diukur dan dievaluasi untuk jangka waktu tertentu (Ramila, Sing, \& Vadivelu, 2016). Konsep penilaian kinerja didasarkan pada pentingnya kinerja organisasi yang akan berpengaruh pada suatu proses penilaian (Rusu, Avasilcai, \& Hutu, 2016).

\section{METODE PENELITIAN}

Penelitian ini dilakukan untuk mengetahui gambaran komunikasi kerja, kepuasan kerja, dan komunikasi kerja. Variabel independen dalam penelitian ini yaitu komunikasi kerja (X) yang terdiri dari dimensi downward communication (komunikasi ke bawah), upward communication (komunikasi ke atas),dan lateral communication (komunikas lateral). Sementara kepuasan kerja menjadi variabel intervening (Y) dengan dimensinya yaitu Pay (gaji), Job (pekerjaan), Promotion (promosi), Supervisor (pengawasan), Coworkers (rekan kerja). Serta variabel dependen (Z) yaitu kinerja karyawan dimensinya mencakup quality of work (kualitas pekerjaan), quantity of work performed (kuantitas pekerjaan yang dilakukan), nterpersonal effectiveness (efektivitas interpersonal), Competence (kompetensi) dan Job Knowledge (Pengetahuan).

Penelitian ini dilakukan di Toserba Yogya cabang Sunda,. Penelitian ini dilakukan dalam kurun waktu kurang dari satu tahun, mak metode yang digunakan yaitu cross sectional method. Teknik yang digunakan dalam penelitian ini adalah teknik propability sampling dengan pengambilan jumlah sampel sebanyak 57 karyawan. Teknik pengumpulan data yang digunakan adalah studi kepustakaan, studi lapangan dengan penyebaran kuesioner secara langsung, dan studi literature. Sedangkan teknik analisis data yang dilakukan adalah analisis deskriptif dengan menggunakan tabel frekuensi.

\section{HASIL PENELITIAN DAN PEMBAHASAN}

\section{Gambaran Komunikasi Kerja}

\begin{tabular}{|c|c|c|c|c|}
\hline \multicolumn{5}{|c|}{$\begin{array}{l}\text { Tabel } 1 \\
\text { Rekapitulasi Dimensi Komunikasi Keria }\end{array}$} \\
\hline & Dimensi & $\begin{array}{l}\text { Total } \\
\text { Skor }\end{array}$ & $\begin{array}{l}\text { Skor } \\
\text { Ideal }\end{array}$ & $\%$ \\
\hline \multicolumn{5}{|c|}{ Komunikasi Keria } \\
\hline$\frac{150}{1}$ & Downward Communication & 986 & 1197 & $82,3 \%$ \\
\hline 2 & Upward Communication & 957 & 1197 & $79,8 \%$ \\
\hline 3 & Lateral Communication & 980 & 1197 & $81,8 \%$ \\
\hline \multicolumn{2}{|c|}{ Total } & 2923 & 3591 & $81,3 \%$ \\
\hline
\end{tabular}

Berdasarkan hasil penelitian dari angket yang disebar kepada 57 responden diketahui bahwa komuniksi kerja karyawan Toserba Yogya Cabang Sunda Bandung dalam kategori efektif pada interval 2711,5 sampai 3151,2, dengan perolehan skor 2923 atau 81,3\%. dari skor kriterium. Skor tertinggi berdasarkan hasil jawaban responden terdapat pada dimensi downward communication memperoleh skor sebanyak 986 atau 82,3\%, dari skor ideal.

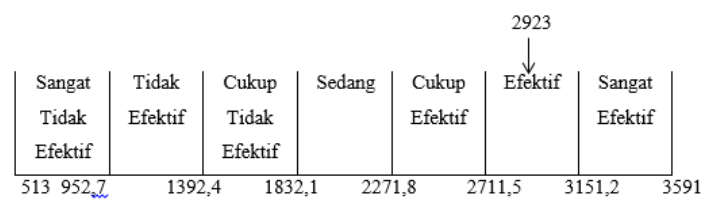

GAMBAR 1

GARIS KONTINUM VARIABEL KOMUNIKASI KERJA

Downward Communication atau komunikasi kebawah merupakan komunikasi yang mengalir dari satu tingkat kelompok atau organisasi ke tingkat yang lebih rendah. Salah satu fungsi utamanya adalah untuk mengetahui seberapa besar pengaruh nya melalui informasi. Selain itu, komunikasi ke bawah dilakukan untuk menyampaikan tujuan, untuk merubah sikap, membentuk pendapat, mengurangi ketakutan dan kecurigaan yang timbul karena salah informasi, mencegah kesalahpahaman karena kurang informasi dan mempersiapkan anggota organisasi untuk menyesuaikan diri dengan perubahan (Muhammad Arni, 2009:108) Kelompok pimpinan menggunakannya untuk menetapkan tujuan, memberikan intruksi kerja, menjelaskan 
kebijakan prosedur atau SOP, memperhatikan masalah-masalah yang ada di perusahaan, dan umpan balik tentang kinerja. Berdasarkan hasil rekapitulasi perhitungan skor diperoleh skor tertinggi terdapat pada dimensi downward communication (komunikasi kebawah). Hal ini dikarenakan pimpinan berani untuk meberikan penjelasan, arahan, tujuan peruasahaan serta berani untuk membrikan masukan kepada bawahan nya. Sedangkan skor terendah terdapat pada dimensi upward communication (komunikasi keatas). Hal ini dikarenakan para karyawan merasa canggung apabila harus berkomunikasi dengan atasannya terutama dalam menyampaikan permaslahan kerja. Seperti yang dijelaskan oleh

( Rivai, 2014:809), bahwa salah satu fakor yang mempengaruhi komunikasi adalah jabatan. Level jabatan biasanya mempengaruhi kelancaran komunikasi diantara pihak-pihak.

Jika dilihat dari tugas dan tanggung jawab, suatu organisasi terbentuk apabila memerlukan usaha lebih dari satu orang untuk menyelesaikannya. Kondisi ini timbul mungkin disebabkan karena tugas itu terlalu besar atau terlalu kompleks untuk ditangani dengan satu orang saja (Muhammad Arni, 2009:24). Dalam hal ini menunjukan instruktur dalam pelatihan memiliki kemampuan yang baik. Adanya tujuan downward communication (komunikasi ke bawah) adalah untuk menyampaikan tujuan, untuk merubah sikap, membentuk pendapat, mengurangi ketakutan dan kecurigaan yang timbul karena salah informasi, mencegah kesalahpahaman karena kurang informasi dan mempersiapkan karyawan untuk menyesuaikan diri dengan perubahan (Muhammad Arni, 2009). Seorang pimpinan harus lebih memperhatikan komunikasi dengan bawahannya, dan memahami cara-cara mengambil kebijaksanaan terhadap bawahannya. Keberhasilan organisasi dilandasi oleh perencanan yang tepat dan seorang pimpinan organisasi yang memiliki jiwa kepemimpinan. Kedua hal tersebut merupakan modal utama untuk kemajuan organisasi yang dipimpinnya.

Sementara skor terendah terdapat pada dimensi upward communication (komunikasi ke atas) dengan skor sebesar 957 atau 79,8\% dari skor ideal. Komunikasi ke atas mengacu pada pesan atau informasi yang dikirim dari tingkat bawah ke tingkat atas dalam hirarki organisasi. Para karyawan menggunakan saluran komunikasi ini sebagai kesempatan untuk mengungkapkan ide atau gagasan yang mereka ketahui dan membantu para pegawai untuk menerima jawaban yang lebih baik tentang masalah dan tanggung jawabnya (Mulyana, 2005:103).

Upward Communication atau komunikasi ke atas merupakan aliran pesan dari tingkatan lebih rendah ke tingkat organisasi yang lebih tinggi. Komunikasi ke atas berfungsi untuk memberikan informasi mengenai pekerjaan karyawan, masukan mengenai pekerjaan kepada pimpinan serta penyampaian permasalahan yang dihadapi jaryawan dalam organisasi yang berkaitan dengan pekerjaannya. Pemberian laporan diartikan sebagai pemberian umpan balik dari karyawan kepada pimpinan atas pekerjaannya, masukan pekerjaan merupakan harapan yang dikemukakan karyawan untuk dipertimbangkan oleh pimpinan serta penyampaian permasalahan yang dihadapi atau penyampaian pendapat karyawan dalam bekerja. Para karyawan menggunakan saluran komunikasi ini sebagai kesempatan untuk mengungkapkan ide atau gagasan yang mereka ketahui dan membantu para karyawan untuk menerima jawaban yang lebih baik tentang masalah dan tanggung jawabnya.

Komunikasi kerja memainkan peran penting di dalam organisasi. Komunikasi keja yang efektif sangat dibutuhkan oleh karyawan di tingkatan manajemen bawah dan menengah serta tingkatan manajemen puncak. Komunikasi kerja yang efektif diharapkan mampu memberikan pengaruh terhadap kepuasan kerja dan kinerja karyawan. Dengan demikian perusahaan perlu memahami dan memperbaiki kemonukasi baik secara vertikal maupun secara horizontal, karena komunikasi tidak hanya berfungsi sebagai alat penyampai informasi, lebih dari itu komunikasi dapat digunakan sebagai alat untuk memotivasi. ekspresi emosi dan pengendali (Verma, 2013).

\section{Gambaran Kepuasan Kerja}

\begin{tabular}{|c|c|c|c|c|}
\hline No. & Dimensi & $\begin{array}{l}\text { Total } \\
\text { Skor }\end{array}$ & $\begin{array}{l}\text { Skor } \\
\text { Ideal }\end{array}$ & $\%$ \\
\hline \multicolumn{5}{|c|}{ Kepuasan Kerja Karyawan } \\
\hline & Pekerjaan $(J o b)$ & 1546 & 1995 & $77,4 \%$ \\
\hline 2. & Gaji (Pay) & 1636 & 1995 & $81,9 \%$ \\
\hline 3. & Promosi (Promotion) & 929 & 1197 & $77,5 \%$ \\
\hline 4. & Pengawasan (Supervision) & 642 & 798 & $80,4 \%$ \\
\hline & Rekan Kerja (Co-worker) & 1269 & 1596 & $79,4 \%$ \\
\hline \multicolumn{2}{|r|}{ Total } & 6022 & 7581 & $79,3 \%$ \\
\hline
\end{tabular}

Berdasarkan hasil penelitian dari angket yang disebar kepada 57 responden diketahui bahwa Kepuasan kerja kerja karyawan Toserba Yogya Cabang Sunda Bandung dalam kategori tinggi pada daerah interval 5724,4 sampai 6652,68 dengan perolehan skor 6022 atau 79,3\% dari skor kriterium. Skor tertinggi berdasarkan hasil jawaban responden terdapat pada dimensi gaji (Pay) memperoleh skor sebanyak 1636 atau

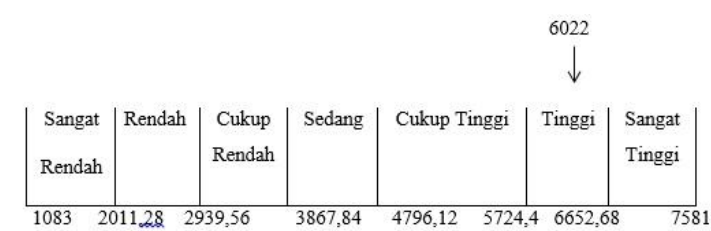

GAMBAR 2 
$81,9 \%$, dari skor ideal.

Suatu organisasi harus memperhatikan hak dan kewajibannya terhadap karyawan. Tidak hanya organisasi yang berhak mendapatkan kinerja yang baik dari karyawan, akan tetapi organisasi juga harus bisa memperhatikan kewajibannya salah satunya yaitu memperhatikan gaji atau upah yang diberikan kepada karyawan. Gaji merupakan faktor pemenuh kebutuhan hidup karyawan yang dianggap layak atau tidak. Seorang karyawan akan merasa senang ketika imbalan yang mereka terima sesuai dengan apa yang mereka kerjakan, sehingga karyawan akan merasa puas dan akan bekerja lebih baik. Gaji merupakan apa yang diberikan perusahaan kepada karyawan dan harus sesuai dengan apa yang mereka kerjakan, yaitu adanya keadilan serta ketepatan dalam pemberian imbalan tersebut,(James L.Gibson, 2012:102)

Dalam hal ini menunjukan bahwa karyawan sudah merasa puas dengan gaji yang diberikan perusahaan karena sudah sesuai dengan jabatan, lama bekerja, UMR pemerintah Bandung, dan juga pemberian gaji yang tepat waktu. Namun terkadang karyawan masih beranggapan bahwa gaji tersebut belum bisa mencukupi kebutuhan hidup. Gaji merupakan balas jasa dalam bentuk uang yang diterima karyawan sebagai konsekuensidari kedudukan sebagai karyawan yang memberikan sumbangan dan pikiran dalam mencapai tujuan perusahaan ( Rivai, 2014:360). Gaji yang ditetapkan perusahaan merupakan salah satu sumber kepuasan bagi karyawan. Karyawan yang bekerja di perusahaan pada dasarnya mempunyai serangkaian kebutuhan yang harus dipenuhi. Gaji yang diterima setiap bulan dapat digunakan untuk memenuhi kebutuhan primer sehari-hari.

Karyawan pada umumnya mengharapkan gaji yang ditetapkan secara adil dan memadai untuk mencukupi kebutuhan setiap bulannya. Tercukupinya kebutuhan primer tersebut akan berdampak pada rasa puas dalam bekerja, sehingga karyawan dapat bersemangat dalam bekerja yang pada akhirnya akan mendukung tingkat produktivitas perusahaanPemberian gaji dari perusahaan kepada karyawan bertujuan agar karyawan merasa puas dengan jerih payahnya sehingga karyawan diharapkan akan bekerja dengan baik. Sebab tenaga kerja manusia mempunyai perasaan sehingga tidak dapat diperas sedemikian rupa demi kepentingan perusahaan saja (Saqib Usman, M. Tahir Akbar, 2013).

Sedangkan untuk skor terendah yaitu pengawasan (supervision) dengan perolehan skor sebesar 642 atau 80,4\% dari skor ideal. Mathis dan Jackson (2010: 303), menyatakan bahwa pengawasan merupakan sebagai proses pemantauan kinerja karyawan berdasarkan standar untuk mengukur kinerja, memastikan kualitas atas penilaian kinerja dan pengambilan informasi yang dapat dijadikan umpan balik pencapaian hasil yang dikomunikasikan ke para karyawan. Pengawasan merupakan proses yang dilakukan oleh pimpinan yang bertujuan untuk menerapkan pekerjaan bersama-sama, serta menilai dan mengoreksi pekerjaan agar tetap sesuai dengan tujuan semula. Pengawasan juga merupakan sebuah proses di dalam menetapkan ukuran dari kinerja dan juga pengambilan tindakan yang dapat mendukung dalam pencapaian hasil yang diharapkan agar sesuai dengan kinerja yang sudah ditetapkan. Kepuasan kerja dapat diukur dari bagaimana supervisi perusahaan atau organisasi kepada karyawan dalam hal ini berkaitan dengan pengawasan kerja dan seberapa sering pimpianan membimbing karyawan dalam bekerja. Menurut (James L.Gibson, 2012:102) pengawasan adalah kemampuan atasan untuk menunjukkan minat dan perhatian para karyawan.

Suatu pengawasan dapat dikatakan efektif apabila sistem pengawasan tersebut sudah memenuhi standar yang telah ditetapkan dan biasanya sesuai dengan prinsip fleksibelitas perusahaan. maka dari itu proses pengawasan merupakan hal penting dalam menjalankan kegiatan organisasi, oleh karena itu setiap pimpinan harus dapat menjalankan fungsi pengawasan sebagai salah satu fungsi manajemen Pengawasan yang dilakukan oleh pimpinan organisasi akan memberikan implikasi terhadap pelaksanaan rencana, sehingga pelaksanaan rencana akan baik jika pengawasan dilakukan secara baik, dan tujuan baru dapat diketahui tercapai dengan baik atau tidak setelah proses pengawasan dilakukan. Dengan demikian peranan pengawasan sangat menentukan baik buruknya pelaksanaan suatu rencana (Qureshi \& Hamid, 2017).

Pengawasan dikatakan sangat penting karena pada dasarnya manusia sebagai objek pengawasan mempunyai sifat salah dan khilaf. Oleh karena itu manusia dalam organisasi perlu diawasi, bukan mencari kesalahannya kemudian menghukumnya, tetapi mendidik dan membimbingnya. Menurut (Dizgah et al., 2012) kepuasan kerja karyawan sangat penting bagi organisasi, karena kepuasan kerja karyawan dapat memungkin karyawan untuk tetap bertahan dalam perusahaan dan terus memberikan kotribusi positif terhadap kemajuan dan tujuan perusahaan. Karyawan yang merasa puas terhadap pekerjaannya dan menggangap pekerjaannya sebagai sesuatu yang menyenangkan akan cenderung memiliki kinerja yang baik. Dengan demikian, karyawan yang 
puas lebih menyukai situasi kerjanya daripada karyawan yang tidak puas yang tidak menyukai situasi kerjanya. Sehingga, memiliki karyawan yang puas terhadap pekerjaannya akan memudahkan organisasi dalam mencapai tujuannya.

\section{Gambaran Kinerja Karyawan}

Tabel 3

\begin{tabular}{lllll}
$\begin{array}{l}\text { REKAPITULASI DIMENSI KINERJA KARYAWAN } \\
\text { No }\end{array}$ & $\begin{array}{l}\text { Total } \\
\text { Skor }\end{array}$ & $\begin{array}{c}\text { Skor } \\
\text { Ideal }\end{array}$ & $\%$ \\
\hline Kinerja Karyawan & & & \\
\hline 1 & Quality of Work & 1589 & 1995 & $79,6 \%$ \\
2 & Quantity of Work & 955 & 1197 & $79,7 \%$ \\
3 & Interpersonal Effectiveness & 912 & 1197 & $76,1 \%$ \\
4 & Competence & 1216 & 1596 & $76,7 \%$ \\
5 & Job Knowledge & 1160 & 1596 & $77,3 \%$ \\
\hline \multicolumn{2}{r}{ Total } & $\mathbf{5 8 3 2}$ & $\mathbf{7 5 8 1}$ & $\mathbf{7 7 , 8 \%}$ \\
\hline
\end{tabular}

Berdasarkan hasil penelitian dari angket yan disebar kepada 57 responden dapat diketahui bahwa kinerja karyawan Toserba Yogya Cabang Sunda Bandung dalam kategori tinggi pada daerah interval 5724,4 sampai 6652,68 dengan perolehan skor 5832 dari skor kriterium.. Skor tertinggi berdasarkan hasil jawaban responden terdapat pada dimensi kualitas kerja (quality of work) dengan jumlah skor 1589 atau $79,6 \%$ dari skor ideal.

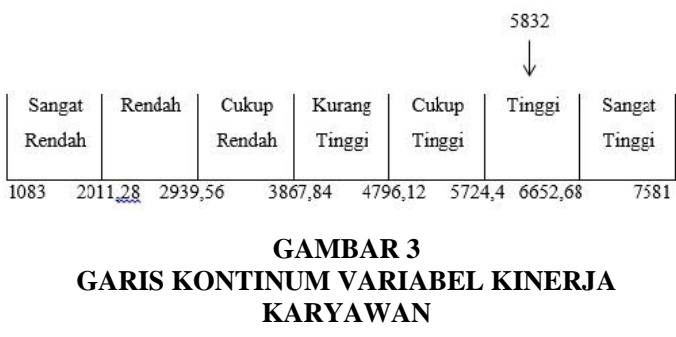

Quality of work atau kualitas kerja merupakan sejauh mana mutu seorang karyawan dalam melaksanakan pekerjaanya. Seseorang untuk mencapai kinerja yang baik haruslah memiliki hasil kerja yang baik pula sesuai tugas dan tanggung jawabnya atau sesuai perannya di perusahaan. Apabila kualitas kerja karyawan tinggi maka kinerja karyawan tersebut akan dianggap baik oleh perusahaan. Dalam hal ini meliputi kesesuaian dengan strandar, teliti dalam bekerja dan mampu mengurangi kesalahan dalam bekerja. Kualitas kerja dicapai karyawan berdasarkan syarat-syarat kesesuaian dan kesiapannya. Jika hasil yang dicapai oleh karyawan tersebut tinggi maka kinerja dari karyawan tersebut dianggap baik oleh pihak perusahaan. Dalam hal ini menunjukan bahwa kualitas kerja (quality of work) dapat berjalan dengan baik. Seseorang untuk mencapai kinerja yang baik haruslah memiliki hasil kerja yang baik pula sesuai tugas dan tanggung jawabnya atau sesuai perannya di perusahaan. Apabila kualitas kerja karyawan tinggi maka kinerja karyawan tersebut akan dianggap baik oleh perusahaan (Tasdemir, 2014). Kualitas dalam hal ini dimaksudkan untuk memperoleh jawaban seberapa baik karyawan dalam bekerja dilihat dari segi mutu. Hubungan antara Kualitas Kehidupan Kerja terhadap Kinerja Karyawan. Kualitas kehidupan kerja merupakan masalah utama yang patut mendapatkan perhatian organisasi (Lewis et,al, 2001). Hal ini merujuk pada pemikiran bahwa kualitas kehidupan kerja dipandang mampu untuk meningkatkan peran serta dan sumbangan para anggota atau karyawan terhadap organisasi. Adanya kualitas kehidupan kerja juga menumbuhkan keinginan para karyawan untuk tetap tinggal dalam organisasi.

Sedangkan untuk skor terendah yaitu Interpersonal effectiveness (Efektivitas Hubungan Interpersonal) yaitu sebesar 912 atau $76,1 \%$ dari skor ideal. Hal tersebut dikarenakan hubungan yang terjalin antara karyawan dan rekan kerja masih belum berjalan efektif, terdapat beberapa karyawan yang belum terbiasa apabila bekerjasama dengan rekan kerja dalam menyelesaikan pekerjaannya, tetapi karyawan sudah mampu untuk bertukar pikiran apabila mengalami permasalahan dalam bekerja. Hubungan Interpersonal adalah interaksi antara seseorang dengan orang lain dalam situasi kerja dan dalam organisasi sebagai motivasi untuk bekerja sama secara produktif.

Hubungan Interpersonai sangat dibutuhkan dalam kegiatan didunia kerja, agar atasan maupun bawahan dapat lebih memahami kinerja setiap karyawan. Interpersonal effectiveness (Efektivitas Hubungan Interpersonal) merupakan hubungan yang terdiri dari dua orang atau lebih yang saling bergantung satu sama lain dan menggunakan pola interaksi yang tetap. Menurut Kathleen S. Verderber ((Budyatna \& Ganiem, 2011)) komunikasi interpersonal adalah suatu proses di mana orang dapat menciptakan dan mengelola hubungan mereka, melaksanakan tanggung jawab secara timbal balik dalam menciptakan makna

Hubungan interpersonal yang efektif sangat penting bagi anggota organisasi khususnya karyawan yang diharapkan dapat membawa hasil pertukaran informasi dan saling pengertian (mutual understanding) dengan sesame rekan kerja. Dalam hal ini efektivitas hubungan interpersonal dapat diukur melalui kerjasama dengan rekan kerja , kerjasama dengan pimpinan, mampu bekerja dalam tim dan mampu bekerja sendiri (Afriyadi, 2015). Saat seseorang tidak merasa senang dengan situasi kerjanya biasanya mereka mengatakan bahwa tidak puas dalam pekerjaannya. Ada dua hal yang menyebabkan kurangnya hubungan interpersonal antar 
karyawan, yaitu pertama apabila orang tersebut tidak mendapatkan informasi yang dibutuhkan untuk melaksanakan pekerjaannya dan yang kedua, apabila hubungan sesama teman kerja kurang baik dalam menjalin hubungan atau pun menjalin komunikasi. (Darijani, Soltani, \& Pourroostaei, 2014).

Upaya untuk meningkatkan kinerja karyawan terbukti mampu dilakukan dengan meningkatkan kepuasan kerja, maka penulis merekomendasikan Toserba Yogya Cabang Sunda Bandung untuk lebih memperhatikan kesempatan promosi kerja terhadap karyawan karena pada dasarnya promosi adalah langkah menawarkan kesempatan untuk pertumbuhan pribadi yang lebih baik, tanggung jawab yang lebih besar, dan peningkatan status sosial yang lebih tinggi. Kinerja karyawan yang baik adalah salah satu faktor yang sangat penting dalam upaya puntuk meningkatkan produktivitas perusahaan. Kinerja merupakan indikator dalam menentukan bagaimana usaha untuk mencapai tingkat produktivitas yang tinggi dalam suatu perusahaan. Dalam hal ini perusahaan perlu terus meningkatkan dan mempertahankan kinerja karyawannya yang salah satunya dapat melalui upaya meningkatkan efektifitas komunikasi dan peningkatan kepuasan kerja karyawan (Irefin \& Mechanic, 2014).

\section{KESIMPULAN DAN REKOMENDASI}

Berdasarkan hasil penelitian yang telah dilakukan menggunakan analisis deskriptif dengan distribusi frekuensi dapat diambil kesimpulan bahwa gambaran komunikasi kerja dalam kategori efektif, kepuasan kerja dalam kategori tinggi dan kinerja karyawan juga dalam kategori tinggi.

Adanya penelitian ini diharapkan dapat membantu peneliti berikutnya dalam melakukan penelitian mengenai komunikasi kerja, kepuasan kerja dan kinerja karyawan dengan menggunkan indikator yang berbeda dari sumber teori yang lebih beragam, dan terhadap objek yang berbeda, karena masih banyaknya keterbatasan dalam penelitian ini, khususnya yang berkaitan dengan metode penelitian dan teknik pengumpulan data.

\section{DAFTAR PUSTAKA}

afriyadi, F. (2015). Efektivitas Komunikasi Interpersonal Antara Atasan Dan Bawahan Karyawan Pt . Borneo Enterprsindo Samarinda, 3(1), 362-376.

Alfayad, Z., Suriani, L., \& Arif, M. (2017). International Review of Management and
Marketing Employee Voice and Job Satisfaction: An Application of Herzberg , s ... Employee Voice and Job Satisfaction: An Application of Herzberg' s Two-factor Theory, 7(January), 150-156.

Armstrong, M. (2014). A handbook of human resource management practice. Human Resource Management.

Awan, A. G., \& Asghar, I. (2014). Impact of Emloyee Job Satisafction on Their Perfomance (A Case Study of Banking Sector Muzzaffargarh District Pakistan). Global Journal of Resource Management, 2(4), 71-94.

Budyatna, M., \& Ganiem, M. L. (2011). Teori Komunikasi antar pribadi. Jakarta: Kencana.

Burma, Z. A. (2014). Human resource management and its importance for today's organizations. International Journal of Education and Social Science, 1(2), 85-94.

Chinomona, R. (2014). T He I Nfluence of the Q Uality of W Orking L Ife on E Mployee J Ob S Atisfaction, J Ob C Ommitment and $\mathrm{T}$ Enure I Ntention in the Sme S Ector in Z Imbabwe. South African Journal of Economic and Management Sciences, 17(4), 363-378.

Darijani, A., Soltani, H., \& Pourroostaei, M. A. (2014). Impact of the effectiveness of organizational communication on job satisfaction through job motivation of employees of Shiraz Telecommunication Company, 30, 43-51.

Dizgah, M. R., Chegini, M. G., \& Bisokhan, R. (2012). Relationship between Job Satisfaction and Employee Job Performance in Guilan Public Sector. Journal of Basic and Applied Scientific Research, 2(2), 1735-1741.

Effendy. (2012). Komunikasi Teori dan Praktek. Bandung: Rosdakarya.

Elnaga, A., \& Imran, A. (2013). The Effect of Training on Employee Performance. European Journal of Business and Management, 5(4), 137-147.

George, J. M., \& Jones, G. R. (2015). Understanding and managing organisational behavior. PhD Proposal (Vol. 1).

Gomez-Mejia, L. R., \& Balkin, D. B. (2012). Management: People, Performance and Change.

Hassan, S. (2016). Impact of HRM Practices on Employee' s Performance. International Journal of Academic Research in Accounting, Finance, and Management, 6(1), 15-22.

Husain, Z. (2013). Effective communication 
brings successful organizational change.

Iqbal, N.; N. A. Z. H. (2013). Impact of performance appraisal on employee ' $\mathrm{S}$ performance involvingthe Moderating Role of Motivation, 3(1), 37-56.

Irefin, P., \& Mechanic, M. A. (2014). Effect of Employee Commitment on Organizational Performance in Coca Cola Nigeria Limited Maiduguri , Borno State Peace Irefin , 2 Mohammed Ali Mechanic. IOSR Journal of Humanities and Social Sciences, 19(3), 3341. Retrieved from www.iosrjournals.org

Ismail, A., Mohamed, N. A. K., \& Rayee, M. R. (2016). Relationship between performance appraisal communication , procedural justice and job satisfaction. Malaysian Journal of Society and Space, 12(2), 15-26.

James L.Gibson.

(2012). organizations_behavior_structure 2012.

John R. Schermerhorn, Jr.Hunt, J. G., Uhl-Bien, M., \& Osborn, R. N. (2011). Organizational Behavior. John Wiley \& Sons.

Kreitner, R., \& Kinicki, A. (2014). Organizational behavioral-Ed. 5. Boston: McGraw-Hill. Boston: McGraw-Hill.

Lubis, F. W. (2013). Peranan Komunikasi Dalam Organisasi, 53-57.

Luthans, F. (2012). Personality, Perception, and Employee Attitudes. Organizational Behavior: An edivence-Based Approach.

Mangkunegara, A. P. (2013). Manajemen Sumber Daya Manusia Perusahaan. Rosdakarya.

Manzoor, S. R., Ullah, H., Hussain, M., \& Ahmad, Z. M. (2011). Effect of Teamwork on Employee Performance. International Journal of Learning and Development, 1(1), 110-126.

Masharyono. (2015). Pengaruh Job Characteristics terhadap Semangat Kerja Pegawai (Survey pada Pegawai PNS di Lingkungan Disparbud Jabar). Jurnal Riset Akuntansi Dan Keuangan.

Masharyono, \& Senen, S. H. (2015). Analisis Job Performance Pegawai Honorer Administrasi Dengan Kompetensi dan Job Characterostics dalam Mendukung Universitas Pendidikan Indonesia Mencapai Leading and Outstanding. Fokus Ekonomi, 10(2), 120-137.

Masharyono, Sumiyati, T. (2016). Physical Work Environment Effect on Employee Productivity of Textile Industry. Advances in Economics, Business and Management Research, 15, 630-632.

Mathis, R. L., Jackson, J. H., Valentine, S. R., \& A.Meglich, P. (2017). Human Resource Management, Fifteenth Edition. United State America: Cengage Learning.
Muhammad Arni. (2009). Komunikasi Organisasi, Jakarta, Bumi Aksara.

Mulyana, D. (2005). Ilmu Komunikasi Suatu Pengantar. Bandung: Remaja Rosdakarya.

Noe, R. A. (2015). Fundamentals of Human Resource Management.6th Edition. Doug Hughes.

Nzuve, P. S. N. M. (2015). Factors Perceived To Influence Employees ' Performance; a Case of the Kenyan State Law Office, 2(3), 214-220.

Pan, S., \& Degree, L. A. (2015). ISSN : 23211784 International Journal in Management and Social Science (Impact Factor- 3 . 25 ) International Journal in Management and Social Science ISSN : 2321-1784 International Journal in Management and Social Science ( Impact Factor- 3 . 25 ) Inte. International Journal in Management and Social Science, 03(02), 718-725.

Poppy, R. (2014). Komunikasi Organisasi.

Qureshi, M. A., \& Hamid, A. (2017). Impact of Supervisor Support on Job Satisfaction: A Moderating role of Fairness Perception, 7(3), 235-242.

Ramila, M., Sing, R., \& Vadivelu, S. (2016). Performance Appraisal in India - A Review. International Journal of Applied Engineering Research ISSN, 11(5), 9734562.

Raziq, A., \& Maulabakhsh, R. (2015). ScienceDirect Impact of Working Environment on Job Satisfaction. Procedia Economics and Finance, 23(October 2014), 717-725.

Robbins \& Coulter. (2016). Management. San Diego: Pearson.

Robbins, S., \& Judge. (2015). Organizations Behavior. New Jersey: Pearson.

Rusu, G., Avasilcai, S., \& Huțu, C.-A. (2016). Fascicle Of Management And Technological Engineering Employee Performance Appraisal: A Conceptual Framework, (August).

Saira, H. (2016). Impact of HRM Practices on Perceived Organizational Performance. International Journal of Academic Research, 6(5), 23-30.

SaqibUsman, M. Tahir Akbar, D. M. (2013). Effect of Salary and Stress on Job Satisfaction of Teachers in District Sialkot, Pakistan, 15(2), 68-74.

Senen, S. H. (2008). Pengaruh Motivasi Kerja dan Kemampuan Kerja Karyawan terhadap Produktivitas Kerja Karyawan pada PT. Safilindo Permata, 7, 1-15.

Senen, Sumiyati, \& Juliandiny. (2016). Kompensasi Serta Motivasi Kerja Pada Kinerja Keperawatan Kontrak Rumah Sakit 
Umum Subang, 81-90.

Shaheen, A., Naqvi, S. M. H., \& Khan, M. A. (2013). Employees Training and Organizational Performance: Mediation by Employees Performance. Interdisciplinary Journal of Contemporary Research in Business, 5(4), 490-503.

Singh, A. K. (2014). Role of Interpersonal Communication in Organizational Effectiveness, 1(4), 36-39.

Spaho, K. (2011). Organizational Communication As An Important Factor Of Company Success : Case Study Of Bosnia, 4(2), 390393.

Sumiyati, Masharyono, \& Toyib. (2016). Industry, Physical Work Environment Effect on Employee Productivity of Textile, 630-632.

Talasaz, Z. H., Saadoldin, S. N., \& Shakeri, M. T. (2014). The Relationship between Job Satisfaction and Job Performance among Midwives Working in Healthcare Centers of Mashhad , Iran. Journal of Midwifery and Reproductive Health, 2(3), 157- 164.

Tasdemir, S. A. (2014). Impact of the Quality of Work-life on Organizational Commitment: A Comparative Study on Academicians
Working for State and Foundation Universities in Turkey.

Tourani, A., \& Rast, S. (2012). Effect of Employees , Communication and Participation on Employees , Job Satisfaction: An Empirical Study on Airline Companies in Iran. 2012 2nd International Conference on Economics, Trade and Development, 36, 52-56.

Veithzal Rivai, E. J. S. (2014). Manajemen Sumber Daya Manusia untuk Perusahaan: Dari Teori ke Praktik. Rajawali Pers.

Verma, P. (2013). Relationship between Organisational Communication Flow and Communication Climate, 1(1), 63-71.

Wibowo. (2014). Perilaku Dalam Organisasi (1st-2nd ed.). Jakarta: Rajawali Pers.

Wilson, B. (2012). Manajemen Sumber Daya Manusia. Bandung: Erlangga.

Zameer, H., Alireza, S., Nisar, W., \& Amir, M. (2014). The Impact of the Motivation on the Employee's Performance in Beverage Industry of Pakistan. International Journal of Academic Research in Accounting, Finance and Management Sciences, 4(1), 293-298. 